\title{
Preparation of novel cosmetic white pigment by pyrophosphate treatment of zinc oxide
}

\author{
H. Onoda ${ }^{1 *}$, K. Hayashi ${ }^{1}$ \\ ${ }^{1}$ Kyoto Prefectural University, Department of Informatics and Environmental Sciences, 1-5, \\ Shimogamo Nakaragi-cyo, Sakyo-ku, Kyoto 606-8522, Japan
}

\begin{abstract}
Zinc oxide, which has photocatalytic activity, is used as a white pigment in cosmetics. With cosmetics containing zinc oxide, some sebum on the skin is broken down by the UV rays of the sun. In this study, in order to suppress the photocatalytic activity of zinc oxide, zinc oxide was added to an aqueous solution of sodium pyrophosphate and shaken, so that novel white pigment coated with zinc phosphate having no photocatalytic activity was prepared for use in cosmetics. The chemical composition, powder properties, photocatalytic activity, hue (visible light reflectance and $\mathrm{L}^{*} \mathrm{a}^{*} \mathrm{~b}^{*}$ values), and smoothness of the resulting powder material were studied. Part of the zinc oxide reacted to zinc phosphate by this pyrophosphate treatment. The photocatalytic activity of zinc oxide was suppressed by this zinc phosphate coating. The resulting sample had sufficiently high reflectance in the visible light region and a high $\mathrm{L}^{*}$ value in the $\mathrm{L}^{*} \mathrm{a} \mathrm{b}^{*}$ color space. The treated samples had lower static friction resistance than the original zinc oxide. Judging from the results of photocatalytic activity, $\mathrm{L}^{*}$ value, and smoothness, the optimum conditions were the molar ratio $\mathrm{P} / \mathrm{Zn}$ of $1 / 4$ for $6 \mathrm{~h}$ of shaking the mixture.
\end{abstract}

Keywords: zinc oxide, photocatalytic activity, powder processing.

\section{INTRODUCTION}

Zinc oxide is used as a white pigment in cosmetics [1]. It is well known that this oxide has photocatalytic activity [2]. Therefore, when using cosmetics containing zinc oxide, some sebum on the skin is decomposed by the ultraviolet rays in the sunlight. Several types of technical processes have been investigated and used to limit this effect. For example, composite particles with silicon dioxide have been used as one such technique [3]. However, these particulate materials are too hard to use on the human face. To use it as a white pigment on the human face, a softer material is needed. In addition, microfine zinc oxide is adsorbed through the skin [4]. It is necessary to use a white pigment with a size that is not adsorbed. Phosphates have been used in ceramic materials, catalysts, adsorbents, fluorescent materials, dielectrics, biomaterials, metal surface treatments, fertilizers, detergents, food additives, fuel cells, pigments, and other applications [5, 6]. Phosphate materials are also well known to have a high affinity for living organisms [7]. Therefore, phosphate is expected to be useful as a white pigment for cosmetics.

When using inorganic powders as cosmetic pigments, particle shape and size distribution are important. Homogeneous spherical particles are expected to spread well on the skin [8]. However, too small particles are inappropriate, as pigments can get into the pores of

*h-onoda@kpu.ac.jp

iD https://orcid.org/0000-0001-6267-2783 the skin. Generally, sub-micrometer size pigments are suitable. It is difficult to determine the standard size of white pigment particles used in cosmetics because skin pore size is affected by factors such as age, gender, and climate [9]. In addition, oversized particles are inappropriate because they crack when applied to the skin [10]. Therefore, it is important to control the particle size of the pigment. In previous studies [11, 12], zinc phosphate pigments with no catalytic activity were prepared. These pigments tended to be spherical, homogeneous particles when prepared using additives used in cosmetics. However, the particle size of zinc phosphate was over $1 \mu \mathrm{m}$. These particles were so large that a new process was needed to produce the smaller particles as white pigments. Zinc phosphate, which has no photocatalytic activity, had too many large particles, whereas zinc oxide, which has a small particle size, had photocatalytic activity. In a previous study, zinc oxide was shaken in phosphoric acid at various temperatures to obtain zinc oxide particles coated with zinc phosphate [13]. The target particles have a core-shell structure, the core portion is zinc oxide, and the shell portion is zinc phosphate having no photocatalytic activity. However, the resulting zinc oxide coating with zinc phosphate contained large particles in excess of $10 \mu \mathrm{m}$. Due to the high reactivity of the phosphoric acid treatment, a large amount of zinc phosphate was produced on the surface of zinc oxide. The purpose of this study is to obtain submicrometer-sized white pigments with no photocatalytic activity by controlling the reaction of zinc oxide with sodium pyrophosphate solution.

It is well known that phosphate reacts to various 
condensed phosphates by heating or the like. Since these condensed phosphates have different reactivity from non-condensed orthophosphates, the production of new materials can be expected by using them. In our previous work, a novel cosmetic white pigment was prepared by shaking titanium oxide with condensed phosphoric acid [14]. As a result, condensed phosphates showed to be suitable for mild phosphate coating. In this work, novel white pigments are prepared from zinc oxide and sodium pyrophosphate solution. The chemical composition, powder properties, photocatalytic activity, hue, and smoothness of the resulting samples were studied for cosmetic application.

\section{EXPERIMENTAL}

Sodium pyrophosphate $\left(\mathrm{Na}_{4} \mathrm{P}_{2} \mathrm{O}_{7}\right)$ was synthesized by heating di-sodium hydrogen phosphate $\left(\mathrm{Na}_{2} \mathrm{HPO}_{4}\right)$ at $400{ }^{\circ} \mathrm{C}$ for $5 \mathrm{~h}$ [14]. Zinc oxide was added to sodium pyrophosphate solution (phosphorus: $0.05 \mathrm{~mol} / \mathrm{L}$ ) in various molar ratios of $\mathrm{P} / \mathrm{Zn}=1 / 1,1 / 2,1 / 4$, or $1 / 6$ in a glass tube. These mixtures were shaken in hot water $\left(50{ }^{\circ} \mathrm{C}\right)$ for 1 or $6 \mathrm{~h}$ (rate of shaking: 100 times/min) [14]. The solutions were decantated off, and the powder samples were washed with water, and then dried at $50{ }^{\circ} \mathrm{C}$ over 3 days. All chemicals were of commercial purity and were obtained from Fujifilm Wako Pure Chem. (Japan) and used without further purification.

The crystal phase compositions of these materials were analyzed using X-ray diffraction (XRD). The XRD patterns were recorded with an X-ray diffractometer (MiniFlex, Rigaku, Japan) using monochromated $\mathrm{CuK} \alpha$ radiation. The IR spectra were recorded with a spectrometer (FT-IR 720, Horiba, Japan) using the $\mathrm{KBr}$ disk method. A portion of the sample was dissolved in a nitric acid solution to estimate the ratio of phosphorus to zinc in the sample. These ratios were calculated from the results obtained with a spectrometer (4200 Microwave Plasma Atomic Emission Spectroscopy - MP-AES, Agilent). The particle size distributions of these materials were measured using a centrifugal precipitation particlesize analyzer (SA-CP3L, Shimadzu, Japan).

The cosmetic properties were estimated for the photocatalytic activity, the color phase, and the smoothness. The photocatalytic activity of samples was estimated with the decomposition of methylene blue by radiation at $365 \mathrm{~nm}[15,16]$. The $0.01 \mathrm{~g}$ of sample was placed in $4 \mathrm{~mL}$ of methylene blue solution $\left(1.0 \times 10^{-5}\right.$ $\mathrm{mol} / \mathrm{L}$ ), and then this solution was radiated. The decrease in the absorption at about $660 \mathrm{~nm}$ was estimated for 120 min. The color of phosphate pigments was estimated using ultraviolet-visible (UV-vis) reflectance spectra with a spectrometer (UV2100, Shimadzu, Japan; reference compound: $\mathrm{BaSO}_{4}$ ). The whiteness was also estimated in $\mathrm{L} * \mathrm{a} * \mathrm{~b} *$ color space with a color analyzer (TES135 plus, TES Electr. Electron., Taiwan; average of 5 times). Like the smoothness of sample powders, the static friction resistances on artificial leather were estimated with a portable friction meter (94i-II, Shinto Sci., Japan). The sample powders were spread on the leather, and then a sensor was run over the powders.

\section{RESULTS AND DISCUSSION}

\section{Chemical composition and powder properties}

Fig. 1 presents the XRD patterns of samples prepared in various $\mathrm{P} / \mathrm{Zn}$ ratios for $6 \mathrm{~h}$ of shaking the mixture. All samples indicated the XRD peak pattern of zinc oxide. In previous work conducted under different conditions, the weak peaks of zinc phosphate appeared by phosphoric acid treatment [13]. However, there was no peak of zinc phosphate in this work. The amount of zinc phosphate was considered low. Fig. 2 shows the IR spectra of samples prepared in various $\mathrm{P} / \mathrm{Zn}$ ratios for $6 \mathrm{~h}$. Zinc oxide showed strong absorption at $400-550 \mathrm{~cm}^{-1}$ and no absorption at $1120-950 \mathrm{~cm}^{-1}$. All samples prepared in this work had some peaks in the second region, due to zinc phosphate. The formation of zinc phosphate in the pyrophosphate treatment of zinc oxide was confirmed from the IR results.

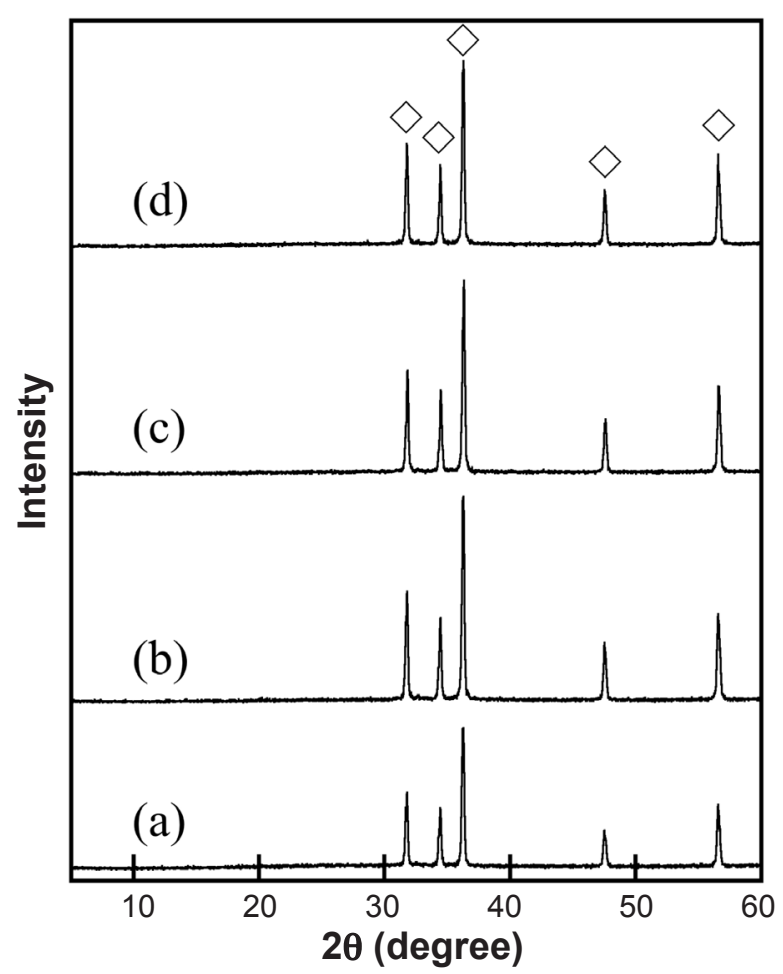

Figure 1: XRD patterns of samples prepared for $6 \mathrm{~h}$ in various $\mathrm{P} / \mathrm{Zn}$ ratios: a) $1 / 1$; b) $1 / 2$; c) $1 / 4$; and d) $1 / 6(\diamond: \mathrm{ZnO})$.

Table I shows the $\mathrm{P} / \mathrm{Zn}$ ratio of samples prepared under various conditions. All samples indicated a ratio below 0.1. If zinc oxide $(\mathrm{ZnO})$ and zinc phosphate $\left[\mathrm{Zn}_{3}\left(\mathrm{PO}_{4}\right)_{2}\right]$ were present in a ratio of $17 / 1$, the $\mathrm{P} / \mathrm{Zn}$ ratio in the sample would be $1 / 10$. Therefore, it can be 


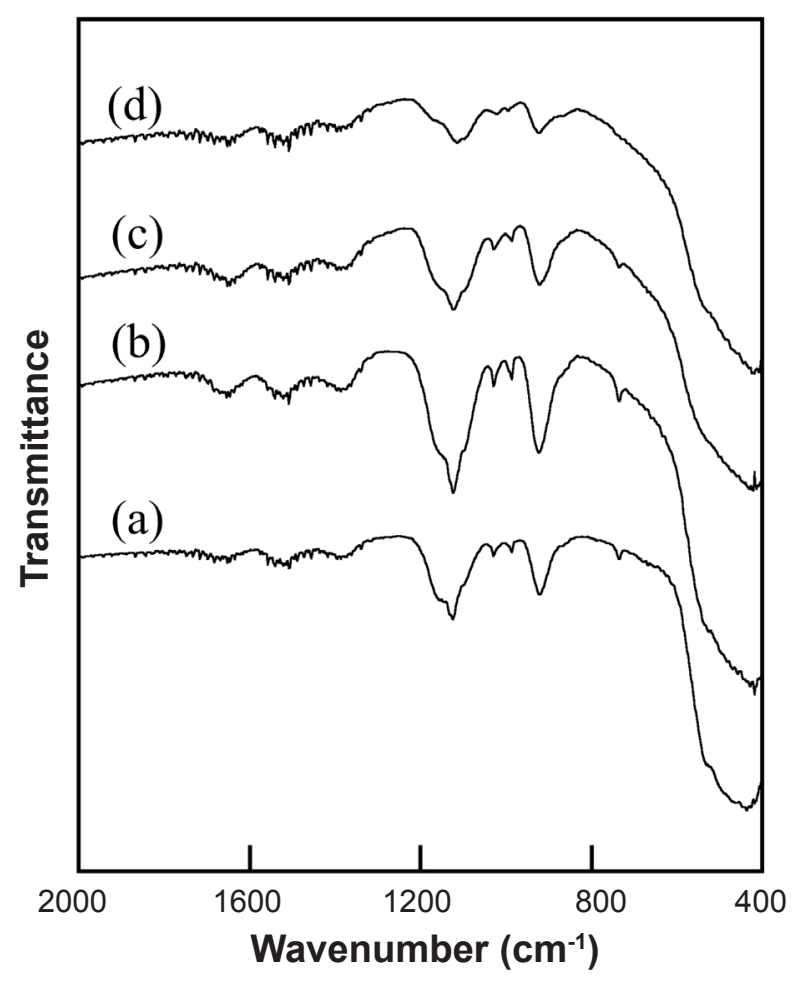

Figure 2: IR spectra of samples prepared for $6 \mathrm{~h}$ in various $\mathrm{P} / \mathrm{Zn}$ ratios: a) $1 / 1$; b) $1 / 2$; c) $1 / 4$; and d) $1 / 6$.

seen that the proportion of zinc phosphate present was quite low. In addition, it can be expected that the larger the amount of pyrophosphate for zinc oxide in the raw material and the longer the shaking time, the easier the reaction. However, in this study, these tendencies could not be confirmed due to the slow progress of the reaction.

The control of particle size is important for the use of inorganic pigments in cosmetic applications [17, 18]. Fig. 3 presents the particle size distribution of samples prepared in various $\mathrm{P} / \mathrm{Zn}$ ratios for $6 \mathrm{~h}$. The original $\mathrm{ZnO}$ indicated a high ratio of smaller particles than $1 \mu \mathrm{m}$. The treatment with sodium pyrophosphate solution increased the proportion of particles with a size of $1 \mu \mathrm{m}$ or larger. Samples prepared in $\mathrm{P} / \mathrm{Zn}=1 / 2$ and $1 / 4$ had a relatively low proportion of large

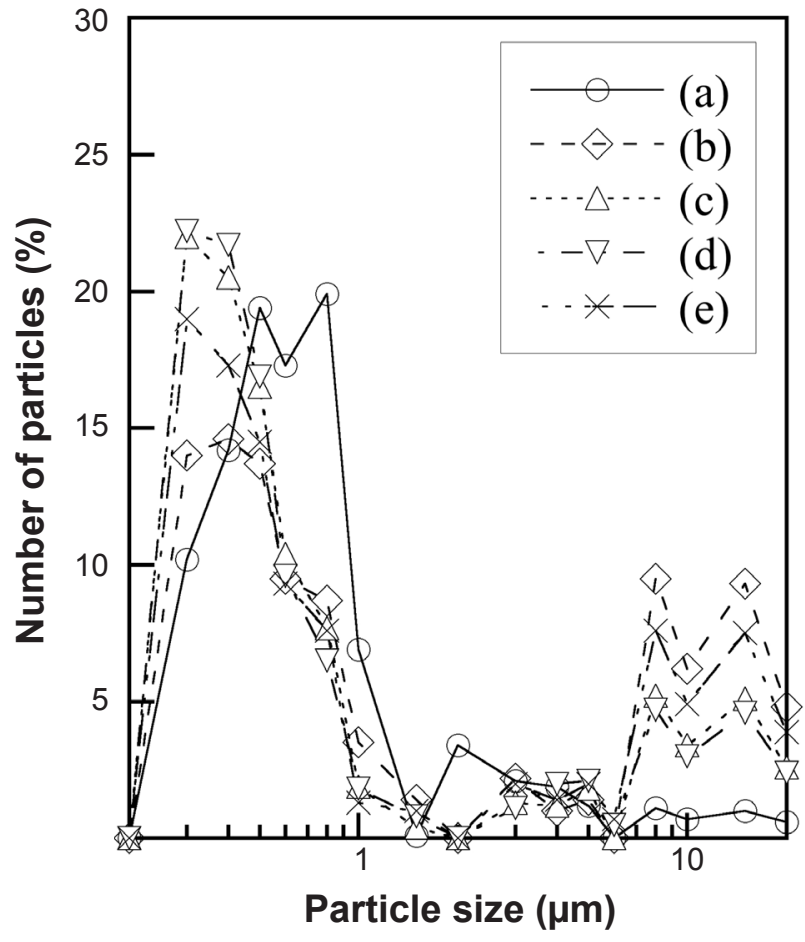

Figure 3: Particle size distribution curves of samples prepared for $6 \mathrm{~h}$ in various $\mathrm{P} / \mathrm{Zn}$ ratios: a) original $\mathrm{ZnO}$; b) $\mathrm{P} / \mathrm{Zn}=1 / 1$; c) $1 / 2$; d) $1 / 4$; and e) $1 / 6$.

particles. The formation of zinc phosphate produced a large particle size, as zinc phosphate tends to form larger particles than zinc oxide $[11,12]$.

\section{Cosmetic properties}

Fig. 4 shows the photocatalytic activity of samples prepared in various $\mathrm{P} / \mathrm{Zn}$ ratios for $6 \mathrm{~h}$. Methylene blue was decomposed with original zinc oxide under UV radiation (Fig. 4b). The photocatalytic activity of zinc oxide was suppressed by the pyrophosphate treatment (Figs. 4c to 4f). The inhibition of photocatalytic activity was associated with the reaction of zinc oxide with sodium pyrophosphate in solution, as zinc phosphate, the expected product on

Table I - $\mathrm{P} / \mathrm{Zn}$ ratio, $\mathrm{L}^{*}$ value, and static friction resistance (SFR) of samples prepared in various conditions.

\begin{tabular}{ccccc}
\hline $\mathrm{P} / \mathrm{Zn}$ in preparation & Time $(\mathrm{h})$ & $\mathrm{P} / \mathrm{Zn}$ in precipitate & L* value & SFR \\
\hline Commercial ZnO & - & 0 & 96.10 & 0.664 \\
$1 / 1$ & 1 & 0.086 & 92.67 & 0.153 \\
$1 / 2$ & 1 & 0.075 & 94.15 & 0.469 \\
$1 / 4$ & 1 & 0.050 & 97.33 & 0.344 \\
$1 / 6$ & 1 & 0.074 & 96.05 & 0.413 \\
$1 / 1$ & 6 & 0.072 & 99.78 & 0.220 \\
$1 / 2$ & 6 & 0.063 & 96.54 & 0.320 \\
$1 / 4$ & 6 & 0.075 & 99.09 & 0.296 \\
$1 / 6$ & 6 & 0.026 & 97.31 & 0.215 \\
\hline
\end{tabular}




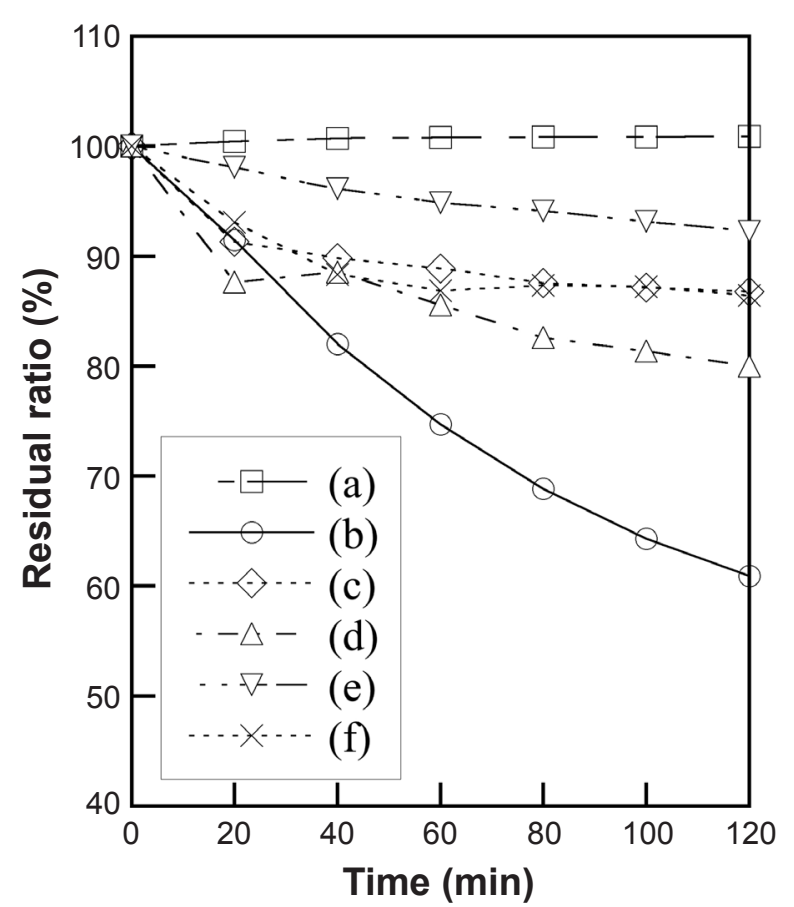

Figure 4: Results of photocatalytic activity of samples prepared for $6 \mathrm{~h}$ in various $\mathrm{P} / \mathrm{Zn}$ ratios: a) blank; b) original $\mathrm{ZnO}$; c) $1 / 1$; d) $1 / 2$; e) $1 / 4$; and f) $1 / 6$.

the particle surface, had no photocatalytic activity [11, 12]. Among them, the sample prepared in $\mathrm{P} / \mathrm{Zn}=1 / 4$ had the lowest photocatalytic activity.

Fig. 5 shows UV-vis reflectance spectra of samples treated in various $\mathrm{P} / \mathrm{Zn}$ ratios for $6 \mathrm{~h}$. All samples indicated high reflectance at the visible light region. Zinc phosphate had high reflectance at the ultraviolet range, therefore samples were expected to have some reflectance at that range [19, 20]. However, the reflectance of all the samples prepared in this study was low in the ultraviolet region due to the low reaction rate. The color of sample powder was also estimated by $\mathrm{L}^{*} \mathrm{a} \mathrm{b}^{*}$ color space. The $\mathrm{L} *$ (lightness) value of samples prepared under various conditions is shown in Table I. The resulting samples were suitable as white pigments, as all samples showed more than 90 . In a previous study [20], some samples prepared with uncondensed phosphoric acid had an $L^{*}$ value of less than 90 . It was found that the condensed phosphate solution was superior in maintaining high whiteness. In particular, samples prepared in $\mathrm{P} / \mathrm{Zn}=1 / 1$ and $1 / 4$ for $6 \mathrm{~h}$ indicated high whiteness. These $\mathrm{L}^{*}$ results were corresponding with the UV-vis reflectance spectra of samples.

As described, the highly smooth pigment spreads well on the skin. The smoothness of the powder is also important for cosmetics [21]. Table I shows the static friction resistance of samples prepared under various conditions. The low static friction resistance means high smoothness. Zinc oxide measured in this condition was 0.664 . All samples prepared in this work indicated lower static friction resistance than zinc oxide. This indicated that samples in this work are suitable for use as a white pigment for cosmetics. Especially, samples prepared in $\mathrm{P} / \mathrm{Zn}=1 / 1(1$ and $6 \mathrm{~h})$ indicated high smoothness.

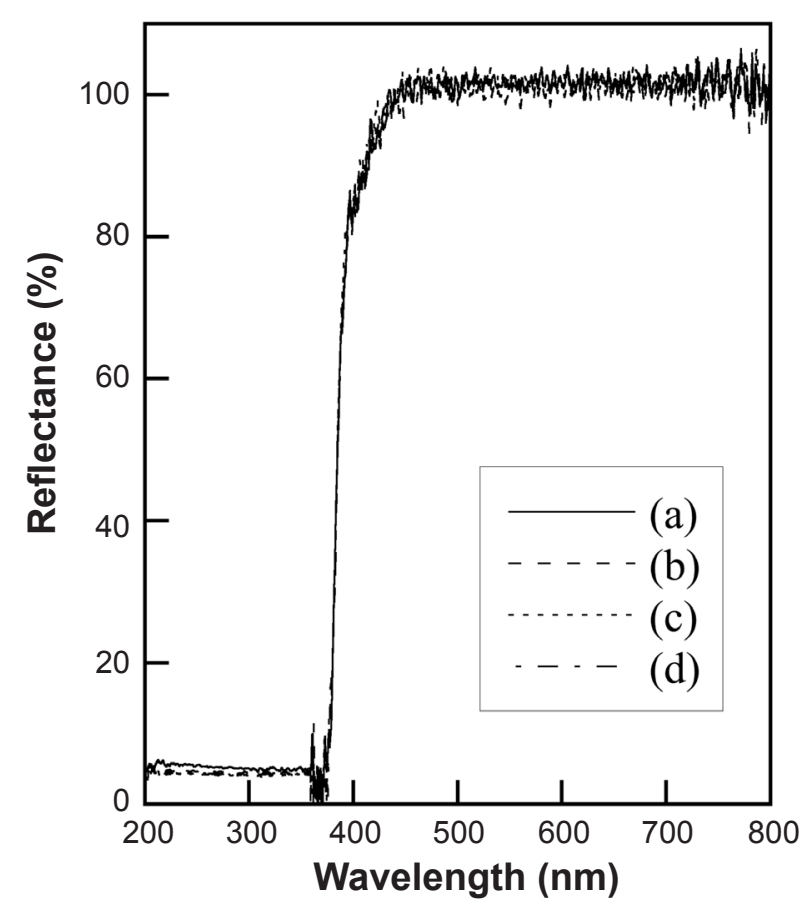

Figure 5: UV-vis reflectance spectra of samples prepared for $6 \mathrm{~h}$ in various $\mathrm{P} / \mathrm{Zn}$ ratios: a) $1 / 1$; b) $1 / 2$; c) $1 / 4$; and d) $1 / 6$.

In previous studies with uncondensed phosphoric acid, the lowest static friction resistance was 0.242 [20]. It was found that using a condensed phosphate solution is useful for producing a novel white pigment for cosmetics.

\section{CONCLUSIONS}

Zinc oxide was shaken in sodium pyrophosphate solution at various $\mathrm{P} / \mathrm{Zn}$ ratios for 1 or $6 \mathrm{~h}$. Part of the zinc oxide reacted to zinc phosphate by this pyrophosphate treatment. The processed samples had a certain degree of larger particles than $1 \mu \mathrm{m}$. The photocatalytic activity of zinc oxide was suppressed by this treatment. The resulting samples had sufficiently high reflectance at the visible light region and high $\mathrm{L}^{*}$ values in $\mathrm{L}^{*} \mathrm{a} \mathrm{b}^{*}$ color space. The treated samples had lower static friction resistance than the original zinc oxide. The most suitable conditions were $P / Z n=1 / 4$ for $6 h$ from photocatalytic activity, $L^{*}$ value, and smoothness.

\section{ACKNOWLEDGEMENTS}

We are grateful to Prof. Yoshiyuki Kojima, Nihon University, Japan, for MP-AES measurements. This work was supported by JSPS KAKENHI Grant Number JP17K60020.

\section{REFERENCES}

[1] N.A. Monteiro-Riviere, K. Wiench, R. Landsiedel, S. Schulte,A.O. Inman, J.E. Rivier, Toxicol. Sci. 123, 1 (2011) 264. [2] A. Kajbafvala, H. Ghorbani, A. Paravar, J.P. Samberg, E. Kajbafvala, S.K. Sadrnezhaad, Superlattices Mictrostruc. 
51, 4 (2012) 512.

[3] G.J. Nohynek, E.K. Dufour, Arch. Toxicol. 86 (2012) 1063.

[4] V.R. Leite-Silva, M.L. Lamer, W.Y. Sanchez, D.C. Liu, W.H. Sanchez, I. Morrow, D. Martin, H.D.T. Silva, T.W. Prow, J.E. Grice, M.S. Roberts, Eur. J. Pharmac. Biopharm. 84, 2 (2013) 297.

[5] W. Weng, R.A. Otaibi, M. Alhumaimess, M. Conte, J.K. Bartley, N.F. Dummer, G.J. Hutchings, C.J. Kiely, J. Mater. Chem. 21, 40 (2011) 16136.

[6] X. Zhou, H. Bai, H. Ma, H. Li, W. Yuan, H. Du, P. Zhang, H. Xin, Mater. Character. 108 (2015) 22.

[7] E. Champion, Acta Biomater. 9, 4 (2013) 5855.

[8] Y. Lee, N.B. Schade, L. Sun, J.A. Fan, D.R. Bae, M.M. Mariscal, G. Lee, F. Capasso, S. Sacanna, V.N. Manoharan, G. Yi, ACS Nano 7, 12 (2013) 11064.

[9] B.Y. Kim, J.W. Choi, K.C. Park, S.W. Youn, Skin Res. Technol. 19, 1 (2011) e45.

[10] S. Yin, Y. Minamidate, S. Tonouchi, T. Goto, Q. Dong, H. Yamane, T. Sato, RSC Adv. 2 (2012) 5976.

[11] H. Onoda, M. Haruki, T. Toyama, Ceram. Int. 40, 2
(2014) 3433.

[12] H. Onoda, M. Haruki, T. Toyama, Int. J. Cosmet. Sci. 36, 4 (2014) 321.

[13] H. Onoda, Y. Sato, J. Mater. Sci. Technol. 32, 5 (2016) 432.

[14] A. Matsukura, H. Onoda, J. Adv. Ceram. 4, 3 (2015) 211.

[15] V. Eskizeybek, F. Sari, H. Gülce, A. Gülce, A. Avci, Appl. Catal. B 119-120 (2012) 197.

[16] B. Lin, X. Li, B. Xu, Y. Chen, B. Gao, X. Fan, Microp. Mesop. Mater. 155 (2012) 16.

[17] T. Goto, S. Yin, T. Sato, T. Tanaka, Int. J. Nanotechnol. 10, 1-2 (2013) 48.

[18] C. Su, H. Tang, K. Chu, C. Lin, Ceram. Int. 40, 5 (2014) 6903.

[19] H. Onoda, M. Chemel, Cerâmica 63, 366 (2017) 197.

[20] H. Onoda, D. Higashide, Ceramics-Silikáty 63, 3 (2019) 291.

[21] L. Xianjuan, X. Haiquan, C. Jing, S. Juncai, Y. Yuxiang, L. Xiangnong, Glass Phys. Chem. 37, 3 (2011) 330.

(Rec. 23/04/2021, Rev. 28/05/2021, Ac. 02/06/2021) 